\title{
Diabetic Nephropathy Can Be Treated with Calcium Dobesilate by Alleviating the Chronic Inflammatory State and Improving Endothelial Cell Function
}

\author{
Yijun Zhou Chaojun Qi Shu Li Xinghua Shao Shan Mou Zhaohui Ni \\ Department of Nephrology, Ren Ji Hospital, School of Medicine, Shanghai Jiaotong University, \\ Shanghai, China
}

\section{Key Words}

Calcium dobesilate - Diabetic kidney disease - Inflammation - Endothelial dysfunction • Urinary albumin

\begin{abstract}
Background/Aims: Diabetic kidney disease (DKD) is a leading cause of end-stage renal disease. However, no effective treatments for this disease are available. Calcium dobesilate $(\mathrm{CaD})$ is widely used to treat diabetic retinopathy. DKD and retinopathy often co-exist and have similar mechanisms of pathogenesis. The aim of the present study was to elucidate the safety and efficacy of $\mathrm{CaD}$ in the treatment of DKD. Methods: In the prospective randomised controlled study, 100 DKD from Type 2 diabetes mellitus (DM) patients with a urinary albumin/ creatinine ratio $(A C R) \geqslant 30 \mathrm{mg} / \mathrm{g}$ and urinary protein level between $150 \mathrm{mg} / 24 \mathrm{~h}$ and $2 \mathrm{~g} / 24$ $\mathrm{h}$ with GFR $>90 \mathrm{ml} / \mathrm{min}$ were enrolled. The patients were randomly divided into the treatment group (500 mg of $\mathrm{CaD}$, administered orally, 3 times per day) and the control group. DKD patients were treated for 3 months. In the case control study, DM patients without proteinuria and healthy individuals were also enrolled. Clinical data and related biochemical parameters were collected. Endothelial function markers (VEGF, ET-1, eNOS, NO) and inflammatory markers (MCP-1, ICAM, PTX3) were detected by ELISA. Results: In the prospective randomised controlled study, the $24 \mathrm{~h}$ urinary albumin and $24 \mathrm{~h}$ urinary protein levels significantly decreased after three months of treatment with $\mathrm{CaD}$ in the patients with $\mathrm{DKD}$, but the cystatin C-based glomerular filtration rate (GFR) remained unchanged. In addition, the levels of inflammatory markers (PTX3, MCP-1, hsCRP, ICAM) and endothelial dysfunction markers (VEGF, ET-1) were significantly reduced compared to pre-treatment levels, NO was significantly increased post treatment. In the case control study, we found that PTX3, MCP-1, ICAM, VEGF and ET-1 levels were positively correlated with urinary albumin in DKD patients, while the NO level was negatively correlated. Logistic regression analysis showed that PTX3, NO and HbAlc were influential factors in DKD. After patients with DKD were treated with CaD for three months,
\end{abstract}




\section{Cellular Physiology Cell Physiol Biochem 2018;51:1119-1133

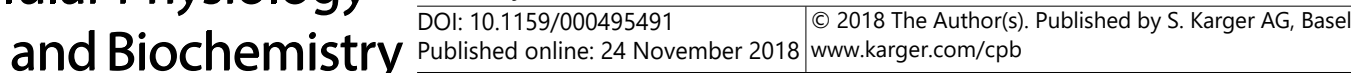 \\ Zhou et al.: Calcium Dobesilate Can Be Used to Treat Diabetic Nephropathy}

the $24 \mathrm{~h}$ urinary albumin and $24 \mathrm{~h}$ urinary protein levels significantly decreased, but the cystatin C-based glomerular filtration rate (GFR) remained unchanged. In addition, the levels of inflammatory markers (PTX3, MCP-1, hsCRP, ICAM) and endothelial dysfunction markers (VEGF, NO, ET-1) were significantly reduced compared to pre-treatment levels. Conclusion: $\mathrm{CaD}$ can be safely and effectively used to treatdiabetic nephropathy.

(C) 2018 The Author(s)

Published by S. Karger AG, Basel

\section{Introduction}

In developed countries, the primary cause of chronic kidney disease (CKD) is diabetic kidney disease (DKD), and approximately $15-25 \%$ of type 1 diabetes mellitus (DM) patients and $30-40 \%$ of type 2 DM patients suffer from DKD[1]. DKD is also the main cause of endstage renal disease (ESRD)[2]. The incidence of DM in China has increased each year [3], and the incidence of DKD is also increasing. According to the results of the Shanghai Dialysis Registration System in 2015, DKD accounted for 14.32\% of year-end ESRD patients and was ranked as the second-leading cause of ESRD in China, after chronic glomerulonephritis (42.4\%). Data from the United States Renal Data System (USRDS) in 2015 showed that ESRD patients with diabetes had not only the highest total hospitalisation rate but also the highest hospitalisation rates for cardiac disease, infection and vascular access infection. The survival of DKD patients was also the lowest among these hospitalised patients. Thus, DKD has become a serious health problem.

In patients with microalbuminuria (urinary albumin excretion rate $>30 \mathrm{mg} / 24 \mathrm{~h}$ ) or macroalbuminuria (urinary albumin excretion rate $>300 \mathrm{mg} / 24 \mathrm{~h}$ ), drugs blocking the reninangiotensin-aldosterone system (RAAS) are the most widely used and include angiotensinconverting enzyme inhibitor (ACEI) and angiotensin II receptor blockade (ARB). These drugs have been shown to delay the development and progression of DKD and improve renal function $[4,5]$. Aldosterone was found to cause renal injury and induce inflammation, fibrosis and necrosis in basic medical science studies [6, 7]. However, 'aldosterone escape' occurred in $40 \%$ of the patients using ACEI and ARB, and their aldosterone levels remained high despite targeting the RAAS. 'Aldosterone escape' is associated with a decline in the glomerular filtration rate (GFR) $[8,9]$. Therefore, in addition to RAAS blockers, we must also explore new methods to delay the progression of DKD.

A long-term prospective study found that endothelial dysfunction and the inflammatory state of types 1 and 2 DM are associated with cardiovascular mortality, kidney disease and all-cause mortality [10]. Moreover, patients with microproteinuria and type 2 DM have elevated inflammatory markers and impaired endothelial function, which can affect patient prognosis $[11,12]$.

Calcium dobesilate $(\mathrm{CaD})$ protects blood vessels and improves circulation by lowering blood viscosity, inhibiting platelet activity and reducing capillary permeability $[13,14]$. Additionally, $\mathrm{CaD}$ also plays a role in inhibiting apoptosis and inflammatory factors [15]. CaD is extensively used to treat diabetic retinopathy [13-17], chronic venous insufficiency [18] and multiple microangiopathic diseases [19]. Renal microvessels and retinal vessels exhibit a similar vascular structure; thus, renal and retinal injury often co-exist in DKD. Although $\mathrm{CaD}$ has a definite therapeutic effect on diabetic retinopathy, the efficacy and safety of CaD have rarely been reported in DKD studies. CaD can improve the renal function of rats with streptomycin-induced acute renal injury, as has been reported in animal experiments [20]. A few studies in clinics also showed that $\mathrm{CaD}$ can be used to treat DKD and reduce albuminuria [21].

In the present study, a cross-sectional study method was first used to explore the endothelial dysfunction and microinflammatory state in patients with DKD. Then, a prospective, randomised controlled trial was conducted to evaluate the efficacy and safety of $\mathrm{CaD}$ in patients with DKD. 


\section{Cellular Physiology Cell Physiol Biochem 2018;51:1119-1133 and Biochemistry Published \begin{tabular}{l|l} 
DOI: 10.1159/000495491 & $\begin{array}{l}\text { (c) } 2018 \text { The Author(s). Published by S. Karger AG, Basel } \\
\text { www.karger.com/cpb }\end{array}$
\end{tabular} \\ Zhou et al.: Calcium Dobesilate Can Be Used to Treat Diabetic Nephropathy}

\section{Materials and Methods}

Cross-sectional study to explore endothelial dysfunction and the microinflammatory state in DKD patients

Subjects. The subjects were divided into three groups: DKD group, DM without proteinuria group, control group. Selection criteria for DKD group were: type 2 DM patients diagnosed in accordance with the 2014 American Diabetes Association (ADA) diagnosis and treatment guidelines; and patients with a albumin/creatinine ratio (ACR) $\geq 30 \mathrm{mg} / \mathrm{g}$ and $24 \mathrm{~h}$ urinary protein between $150 \mathrm{mg}$ and $2 \mathrm{~g}$ in random morning urine samples at least twice in the past 3 months; and patients with the presence of diabetic retinopathy; and patients with no previous history of hypertension and with blood pressure $\leq 140 / 90$ $\mathrm{mmHg}$; and patients with a GFR $\geq 90 \mathrm{ml} / \mathrm{min} / 1.73 \mathrm{~m} 2$; and patients aged 18-70 years. Exclusion criteria for DKD group were: patients with cardiac and hepatic insufficiency; or patients with severe cerebrovascular disease; or patients with haemorrhage and coagulopathy diseases; or patients with ketoacidosis, infection and fever; or pregnant and lactating women. DM without proteinuria group was defined as Type 2 DM patients who had normal urine test results, a GFR $\geq 90 \mathrm{ml} / \mathrm{min} / 1.73 \mathrm{~m} 2$ and no history of hypertension were age and sex matched to the DKD patients enrolled in this study. Control group was defined as healthy individuals who were age and sex matched to the patients and had normal urine test results and renal function were collected from the physical examination centre of our hospital from March 2015 to March 2016.

Informed consent. All patients included in the study signed an informed consent form.

Methods. This part of the study was a three-way age and sex matched case control study (DM patients with proteinuria, no proteinuria and healthy controls). DKD group, DM group and healthy controls who met the inclusion criteria were followed up once.

General conditions included age, sex, blood pressure (systolic blood pressure, diastolic blood pressure and mean arterial pressure), any history of cardiovascular diseases (CVDs) (coronary heart disease, cerebrovascular disease, including haemorrhage and infarction, and peripheral arterial disease) and medication history (e.g., statins). Serum cystatin C (Cys C), creatinine, urea nitrogen, uric acid, routine blood tests, albumin, cholesterol, triglyceride, high-density lipoprotein, low-density lipoprotein, HbAlc, high-sensitivity C-reactive protein (hs-CRP), $24 \mathrm{~h}$ urinary albumin and $24 \mathrm{~h}$ urinary protein were analysed by the biochemical laboratory of our hospital. Levels of serum vascular endothelial growth factor (VEGF), endothelin-1 (ET-1), monocyte chemotactic protein 1 (MCP-1), intercellular adhesion molecule-1 (ICAM), endothelial nitric oxide synthase (eNOS), nitric oxide (NO) and plasma pentraxin 3 (PTX3) were measured by an ELISA. The eNOS kit was manufactured by TSZ (Boston, MA, USA). The VEGF, ET-1, MCP-1, ICAM, NO and PTX3 kits were manufactured by R\&D (Minneapolis, MN, USA). The GFR was calculated according to the CKD-EPIcys equation [22]. Morning fasting peripheral venous blood (7 ml) was collected from all subjects after enrolment. The specimens were placed in ordinary tubes and EDTA anticoagulant tubes and then centrifuged for $30 \mathrm{~min}$ (4, $000 \mathrm{rpm}, 10 \mathrm{~min}$ ). Serum and plasma were separated, placed in Eppendorf tubes and preserved in a $-80^{\circ} \mathrm{C}$ refrigerator. Additionally, $24 \mathrm{~h}$ urine specimens from DKD patients were preserved.

Statistical methods. All data were processed and analysed using the SPSS 20.0 statistical software package. A normal distribution test was conducted before analysis, and the data were considered to conform to a normal distribution when $\mathrm{P}>0.05$. Measurement data that were normally distributed are expressed as the means \pm standard deviation. T-test was performed to compare the two groups. Three groups measurement data comparison used analysis of ANOVA. Data that did not conform to a normal distribution are expressed as medians (quartile) $[\mathrm{M}(1 / 4,3 / 4)]$, and group comparison was performed using a nonparametric test. Count data are expressed as percentages (\%), and group comparison was performed using the chi-squared test. Univariate analysis (Spearman's correlation) was used to test the relationship between urinary protein excretion and various clinical biochemical indices in patients with DKD. The sensitivity and specificity of each index for the prediction of urinary protein excretion were assessed using the receiver operating characteristic (ROC) curve and area under the ROC curve (AUC). Logistic regression was used to test the relationship among HbAlc, serum albumin, hs-CRP, PTX3, eNOS, NO and urinary protein excretion. All tests were bilateral two-tailed tests, and $\mathrm{P}<0.05$ indicated that there were statistically significant differences. 


\section{Cellular Physiology Cell Physiol Biochem 2018;51:1119-1133 and Biochemistry Published \begin{tabular}{l|l} 
DOI: 10.1159/000495491 & $\begin{array}{l}\text { (c) } 2018 \text { The Author(s). Published by S. Karger AG, Basel } \\
\text { www.karger.com/cpb }\end{array}$
\end{tabular} \\ Zhou et al.: Calcium Dobesilate Can Be Used to Treat Diabetic Nephropathy}

Prospective randomised controlled study to observe the efficacy and safety of CaD in patients with DKD

Subjects. In this part, the subjects were DKD patients. Selection and exclusion criteria for DKD patients were same as the cross-sectional study. Withdrawal criteria were as follows: patients with abnormal liver function, with alanine aminotransferase or aspartate aminotransferase levels 2-fold higher than the upper limit of normal values; or patients with the need for the additional use of ACEI orARB; or patients who became pregnant; or patients who developed acute blood loss, such as from gastrointestinalhaemorrhage, cerebral haemorrhage or trauma; or patients who insisted on withdrawal.

Informed consent. All patients included in the study signed an informed consent form.

Methods. The study design in this part of the study was a non-placebo controlled open study design. The DKD patients who met the inclusion criteria were randomly assigned to two groups using the random number method and received three months of treatment. The randomisation process was concealed by sequentially number, opaque, sealed envelopes (SNOSE). The medication group was treated with oral CaD, $500 \mathrm{mg}$ each time, three times per day. The observation group maintained the original hypoglycaemic and hypolipidaemic regimen to evaluate the treatment. The second, third and fourth observation time points were at 1,2 and 3 months after treatment, respectively.

Collection of clinical medical history information was same as the cross-sectional study. Laboratory tests and calculation of the GFR according to the CKD-EPIcys equation were same as the cross-sectional study. Fasting venous blood $(7 \mathrm{ml})$ was collected from all subjects after enrolment in the morning. The specimens were placed in ordinary tubes and EDTA anticoagulant tubes and then centrifuged for $30 \mathrm{~min}$ $(4,000 \mathrm{rpm}, 10 \mathrm{~min})$. The serum and plasma were separated, placed in Eppendorf tubes and preserved in a $-80^{\circ} \mathrm{Crefrigerator}$. The specimens were used to measure routine biochemical indices and serum VEGF, ET- 1 , MCP-1, ICAM, eNOS, NO and PTX3 levels. Additionally, $24 \mathrm{~h}$ urine specimens were collected to measure 24 $\mathrm{h}$ urinary protein and $24 \mathrm{~h}$ urinary albumin. At each follow-up, morning urine specimens were collected to measure urinary albumin. At the end of follow-up, fasting blood was collected to measure routine biochemical indices and serum VEGF, ET-1, MCP-1, ICAM, eNOS, NO and PTX3 levels. We obtained the $24 \mathrm{~h}$ urine specimen for the analysis of $24 \mathrm{~h}$ urinary protein and $24 \mathrm{~h}$ urinary albumin.

Efficacy and safety assessment. Efficacy assessment included: changes in urinary albumin, $24 \mathrm{~h}$ urinary protein and $24 \mathrm{~h}$ urinary albumin level; and serum CysC and GFR calculated using the CKD-EPIcys equation; and blood VEGF, ET-1, MCP-1, ICAM, eNOS, NO and PTX3 levels. Safety assessment included: vital signs, adverse events and blood biochemical indices during medication, as well as severe adverse events, were assessed from enrolment to 1 week after the last administration.

Statistical methods. Same as the cross-sectional study

\section{Results}

Cross-sectional study to explore endothelial dysfunction and the microinflammatory state in patients with $D K D$

General data of the enrolled DKD patients, DM control population and healthy control population. A total of 100 DKD patients who were diagnosed and treated in our hospital from March 2015 to March 2016 were enrolled, in addition to $30 \mathrm{DM}$ patients with normal urine test results and renal function and 30 healthy controls. The DKD patients included 41/100 (41\%)males and 59/100 (59\%) females, with an average age of $(60.18 \pm 11.03)$ years. $15 \%$ $(15 / 100)$ of DKD patients had a history of CVD: there were $7 / 100(7 \%)$ cases of cerebral infarction, $5 / 100(5 \%)$ cases of myocardial infarction, 2/100 (2\%) cases of lower extremity arterial disease and $1 / 100(1 \%)$ case of cerebral haemorrhage history. Two DM patients $2 / 30$ $(6 \%)$ without proteinuria had a history of CVD, with $1 / 30(3 \%)$ case of cerebral infarction and $1 / 30(3 \%)$ case of myocardial infarction. Additionally, the medication history of DKD patients $21 / 100(21 \%)$ included statins, which was not significantly different from the DM group. The populations of the DM control group and the healthy control group were both age 


\section{Cellular Physiology Cell Physiol Biochem 2018:51:1119-1133

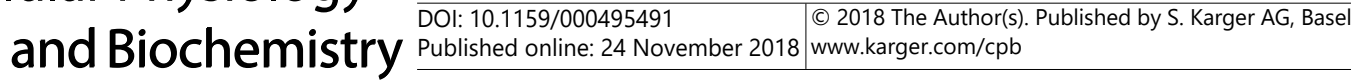

Table 1. Demographic and clinical data of the DKD patients and control populations. Mean \pm SD for normally distributed data and median (range) for non-parametric data. GFR=glomerular filtration rate; $\mathrm{CVD}=$ cardiovascular disease; HDL=high density lipoprotein; hsCRP=high-sensitivity protein; LDL=lowdensity lipoprotein; PTX3=pentraxin 3; HbAlc=glycoseylated hemoglobin; MCP-1=monocyte chemotactic protein 1; ICAM=intercellular cell adhesion molecule-1; VEGF=vascular endothelial growth factor; ET1=endothelin-1; eNOS=endothelial nitric oxide synthase; NO=nitric oxide

\begin{tabular}{|c|c|c|c|c|c|c|c|}
\hline Parameter & 1.DKD & 2. DM patients without proteinuria & 3.control & P-value & 1.vs.2 & 1.vs.3 & 2.vs.3 \\
\hline $\mathrm{n}$ & 100 & 30 & 30 & / & / & / & / \\
\hline Duration of DM (years) & $18.29 \pm 7.43$ & $17.49 \pm 6.71$ & / & / & NS & / & / \\
\hline History of CVD, n(\%) & $15(15)$ & $2(6)$ & / & / & NS & / & / \\
\hline Statin taking history $\mathrm{n}(\%)$ & $21(21)$ & $6(20)$ & / & / & NS & & \\
\hline Age (years) & $60.18 \pm 11.03$ & $58.48 \pm 12.11$ & $56.87 \pm 5.00$ & NS & NS & NS & NS \\
\hline $\operatorname{Sex}(M / F)$ & $41 / 59$ & $16 / 14$ & $15 / 15$ & NS & NS & NS & NS \\
\hline $\mathrm{eGFR}\left[\mathrm{ml} \cdot \min ^{-1} \cdot\left(1.73 \mathrm{~m}^{2}\right)^{-1}\right]$ & $105.81 \pm 12.85$ & $101.62 \pm 12.11$ & $100.23 \pm 9.25$ & NS & NS & NS & NS \\
\hline Total Cholesterol (mmol/L) & $4.88 \pm 1.25$ & $4.78 \pm 1.39$ & $4.61 \pm 1.00$ & NS & NS & NS & NS \\
\hline Triglyceride $(\mathrm{mmol} / \mathrm{L})$ & $1.89 \pm 1.21$ & $1.56 \pm 0.75$ & $1.27 \pm 0.64$ & 0.019 & NS & 0.001 & NS \\
\hline $\mathrm{LDL}(\mathrm{mmol} / \mathrm{L})$ & $2.92 \pm 0.93$ & $2.97 \pm 1.19$ & $2.77 \pm 0.78$ & NS & NS & NS & NS \\
\hline HDL $(\mathrm{mmol} / \mathrm{L})$ & $1.15 \pm 0.31$ & $1.20 \pm 0.34$ & $1.32 \pm 0.32$ & 0.046 & NS & 0.013 & NS \\
\hline HbAlc (\%) & $8.53 \pm 1.96$ & $6.62 \pm 0.63$ & $5.34 \pm 0.32$ & $<0.001$ & $<0.001$ & $<0.001$ & 0.002 \\
\hline Albumin $(\mathrm{g} / \mathrm{L})$ & $42.81 \pm 3.78$ & $45.75 \pm 2.30$ & $45.79 \pm 2.40$ & $<0.001$ & $<0.001$ & $<0.001$ & NS \\
\hline GPT (U/L) & $21.48 \pm 1.30$ & $23.90 \pm 2.40$ & $18.47 \pm 4.22$ & NS & NS & NS & NS \\
\hline GOT(U/L) & $19.71 \pm 7.90$ & $18.48 \pm 5.93$ & $16.57 \pm 6.95$ & NS & NS & NS & NS \\
\hline $\mathrm{SB}(\mathrm{mg} / \mathrm{dl})$ & $11.08 \pm 6.06$ & $11.42 \pm 3.35$ & $11.54 \pm 5.41$ & NS & NS & NS & NS \\
\hline $\mathrm{SB}^{\prime}(\mathrm{mg} / \mathrm{dl})$ & $3.71 \pm 1.58$ & $4.03 \pm 1.11$ & $4.03 \pm 1.51$ & NS & NS & NS & NS \\
\hline hsCRP (mg/l) & $3.08 \pm 0.82$ & $2.51 \pm 0.87$ & $2.39 \pm 0.67$ & NS & NS & NS & NS \\
\hline MCP-1(ng/L) & $197.69 \pm 42.71$ & $158.19 \pm 42.86$ & $150.39 \pm 43.65$ & $<0.001$ & $<0.001$ & 0.016 & NS \\
\hline PTX3(ng/ml) & $8.56 \pm 1.88$ & $6.25 \pm 1.89$ & $5.81 \pm 1.66$ & $<0.001$ & $<0.001$ & $<0.001$ & 0.045 \\
\hline ICAM(ng/L) & $568.30 \pm 103.51$ & $405.88 \pm 106.06$ & $387.17 \pm 100.23$ & $<0.001$ & $<0.001$ & $<0.001$ & NS \\
\hline VEGF(ng/ml) & $1.28 \pm 0.23$ & $0.94 \pm 0.21$ & $0.86 \pm 0.22$ & $<0.001$ & $<0.001$ & $<0.001$ & NS \\
\hline $\mathrm{ET}-1(\mathrm{pg} / \mathrm{ml})$ & $208.95 \pm 38.86$ & $141.43 \pm 36.62$ & $142.53 \pm 37.35$ & $<0.001$ & $<0.001$ & $<0.001$ & NS \\
\hline eNOS(U/L) & $49.12 \pm 9.13$ & $51.43 \pm 13.78$ & $50.53 \pm 9.80$ & NS & NS & NS & NS \\
\hline $\mathrm{NO}$ (umol/L) & $149.27 \pm 34.62$ & $197.87 \pm 37.44$ & $206.48 \pm 43.96$ & $<0.001$ & $<0.001$ & $<0.001$ & NS \\
\hline
\end{tabular}

and sex matched to the patients of the DKD group. The basic data and laboratory biochemical indices of the DKD patients and control populations are detailed in Table 1.

DKD patients had significantly higher PTX3, MCP-1 and ICAM than the DM patients without proteinuria. The mean PTX3 of DKD group was $8.56 \pm 1.88 \mathrm{ng} / \mathrm{ml}$, and that of the DM without proteinuria group was $6.25 \pm 1.89 \mathrm{ng} / \mathrm{ml}$; the level of PTX3 was significantly elevated in the DKD group $(\mathrm{P}<0.001)$. The serum MCP-1 level of the DKD group was $197.69 \pm 42.71 \mathrm{ng} / \mathrm{l}$, and that of the DM without proteinuria group was $158.19 \pm 42.86 \mathrm{ng} / \mathrm{l}$; the MCP-1 level was significantly higher in the DKD group $(\mathrm{P}<0.001)$. The serum ICAM of the DKD group was $568.30 \pm 103.51 \mathrm{ng} / \mathrm{l}$, and that of the DM without proteinuria group was $405.88 \pm 106.06$ $\mathrm{ng} / \mathrm{ml}$; the level of ICAM was significantly higher in the DKD group $(\mathrm{P}<0.001)$. No significant difference was found in hs-CRP among the three groups (Table 1).

DKD patients had significantly higher endothelial cell function-related indices, such as VEGF and ET-1, but lower NO than DM patients without proteinuria. The serum VEGF of the DKD group was $1.28 \pm 0.23 \mathrm{ng} / \mathrm{ml}$, and that of the DM without proteinuria group was $0.94 \pm 0.21 \mathrm{ng} / \mathrm{ml}$; the VEGF level was significantly higher in the DKD group $(\mathrm{P}<0.001)$. The serum NO of the DKD group was $149.27 \pm 34.62 \mu \mathrm{mol} / \mathrm{l}$, and that of the DM without proteinuria group was $197.87 \pm 37.44 \mathrm{ng} / \mathrm{ml}$; the NO level was significantly lower in the DKD group $(\mathrm{P}<0.001)$. The serum ET-1 of the DKD group was $208.95 \pm 38.86 \mu \mathrm{mol} / \mathrm{l}$, and that of the DM without proteinuria group was $141.43 \pm 36.62 \mu \mathrm{mol} / \mathrm{l}$; the ET-1 level was significantly higher in the DKD group $(\mathrm{P}<0.001)$. No significant difference was found in eNOS among the three groups (Table 1).

Inflammatory indices, such as PTX3, MCP-1 and ICAM, as well as endothelial cell functionrelated indices, such as VEGF and ET-1, were positively correlated with 24 h urinary albumin, whereas NO is negatively correlated with $24 \mathrm{~h}$ urinary albumin in DKD patients. Univariate analysis (Spearman's correlation) results showed that inflammatory indices, such as PTX3 $(\mathrm{r}=0.356, \mathrm{P}=0.001), \mathrm{MCP}-1(\mathrm{r}=0.254, \mathrm{P}=0.003)$ and ICAM $(\mathrm{r}=0.247, \mathrm{P}=0.004)$, were positively 


\section{Cellular Physiology Cell Physiol Biochem 2018;51:1119-1133 \begin{tabular}{ll|l} 
and Biochemistry Published onlIne: 24 November 2018 & $\begin{array}{l}\text { @ } 2018 \text { The Author(s). Published by S. Karger AG, Basel } \\
\text { www.karger.com/cpb }\end{array}$ \\
\hline
\end{tabular}

correlated with $24 \mathrm{~h}$ urinary albumin. Additionally, endothelial cell function-related indices, such as VEGF $(\mathrm{r}=0.267, \mathrm{P}=0.002)$ and ET-1 $(\mathrm{r}=0.216, \mathrm{P}=0.012)$, were positively correlated with $24 \mathrm{~h}$ urinary albumin. In contrast, NO $(\mathrm{r}=-0.229, \mathrm{P}=0.027)$ was negatively correlated with $24 \mathrm{~h}$ urinary albumin. Additionally, HbAlc $(\mathrm{r}=0.226, \mathrm{P}=0.009)$ was positively correlated with $24 \mathrm{~h}$ urinary albumin (Table 2) (Fig. 1-8).

Logistic regression analysis showed that PTX3, NO and $H b$ Alc are factors that influence DKD. We introduced age, sex, HbAlc, serum albumin, hs-CRP, PTX3, MCP-1, eNOS and NO of DKD patients and DM patients without proteinuria into the logistic regression equation to explore factors that affected the occurrence of urinary protein excretion. As Table 3 shows, the odds ratio (OR) for the elevation of the plasma PTX3 concentration and $24 \mathrm{~h}$ urinary albumin was 2.761 (95\% confidence interval [CI]: 1.358-5.615, $\mathrm{P}=0.017)$. Thus, an elevation in the PTX3 level suggests a 2.7-fold increase in the risk of DKD. Additionally, HbAlc (OR=3.304, 95\% CI: 1.228-8.884, $\mathrm{P}=0.019)$ was also a risk factor for DKD, whereas NO (OR=0.941, 95\% CI: $0.905-0.979, \mathrm{P}=0.003$ ) was a protective factor for $\mathrm{DKD}$.

PTX3, NO and HbAlc levels of DM patients are predictive of DKD. ROC curve analysis showed that the AUC of HbAlc was 0.832 (95\% CI: 0.762-0.902, $\mathrm{P}<0.001$ ); when the cut-off point was $6.95 \%$, the sensitivity and specificity of the detection were $80.6 \%$ and $85.7 \%$, respectively. The AUC of PTX3 was 0.848 (95\% CI: 0.758-0.938, P<0.001); when the cut-off point was $6.35 \mathrm{ng} / \mathrm{ml}$, the sensitivity and specificity were $79.6 \%$ and $76.2 \%$, respectively (Fig. 9). The AUC of NO was 0.833 (95\% CI: $0.730-0.935, \mathrm{P}<0.001$ ); when the cut-off point was 175.71 $\mu_{\mathrm{mol}} / \mathrm{l}$, the sensitivity and specificity of the detection were $71.4 \%$ and $74.2 \%$, respectively (Fig. 10).

Prospective randomised controlled trial to observe the efficacy and safety of CaD treatment in patients with $D K D$

General conditions. The study enrolled a total of 100 DKD patients who were diagnosed and treated at our hospital from March 2015 to March 2016. A prospective randomised controlled study method was used, and DKD patients were divided into two groups: the treatment group and the clinical observation group. The basic data and laboratory biochemical indices of the patients are shown in Table 4. The treatment group (50 patients) included 24 males and 26 females, with an average age of $(57.97 \pm 11.65)$ years. There were 7 patients (14\%) with a history of CVD: 5 cases of cerebral infarction, 1 case of myocardial infarction and 1 case of lower extremity arterial disease. The observation group ( 50 patients) included 27 males and 23 females, with an average age of $(61.43 \pm 10.03)$ years. There were $8(16 \%)$ patients with a history of CVD: 2 cases of cerebral infarction, 4 cases of myocardial infarction, 1 case of lower extremity arterial disease and 1 case of cerebral haemorrhage history. The basic data of the two groups were matched according to sex, age, CVD history and medication history. Additionally, group comparison revealed no significant difference between the two groups in terms of the various biochemical indices (Table 4). 




Fig. 1. HbAlc positively correlated with $24 \mathrm{~h}$ urine albumin.

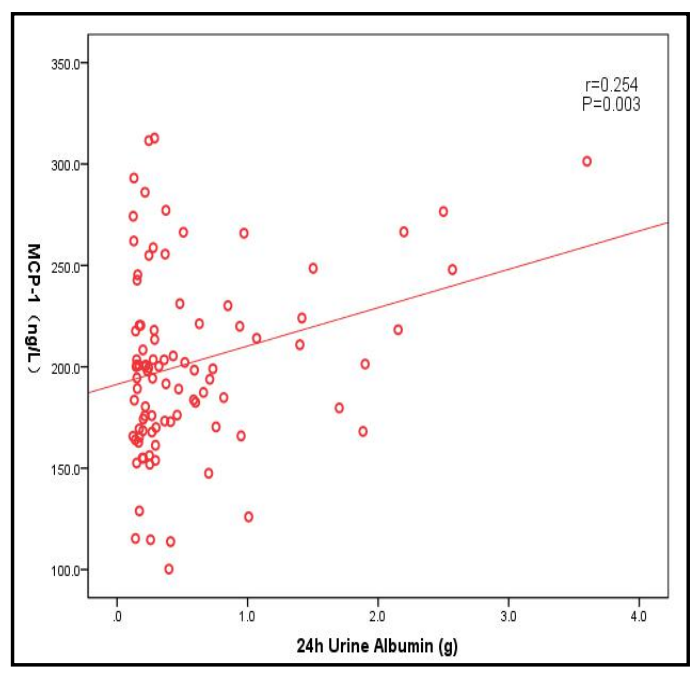

Fig. 3. MCP-1 positively correlated with $24 \mathrm{~h}$ urine albumin.

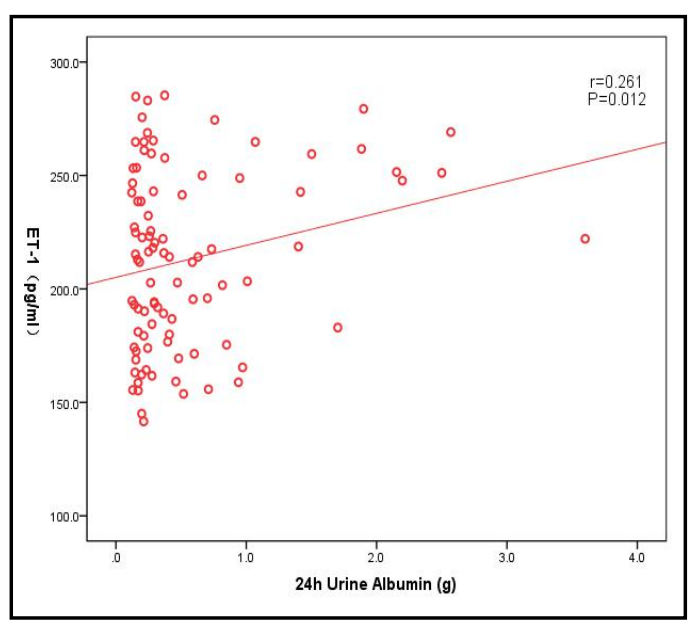

Fig. 5. ET-1 positively correlated with $24 \mathrm{~h}$ urine albumin.



Fig. 2. hsCRP positively correlated with $24 \mathrm{~h}$ urine albumin.

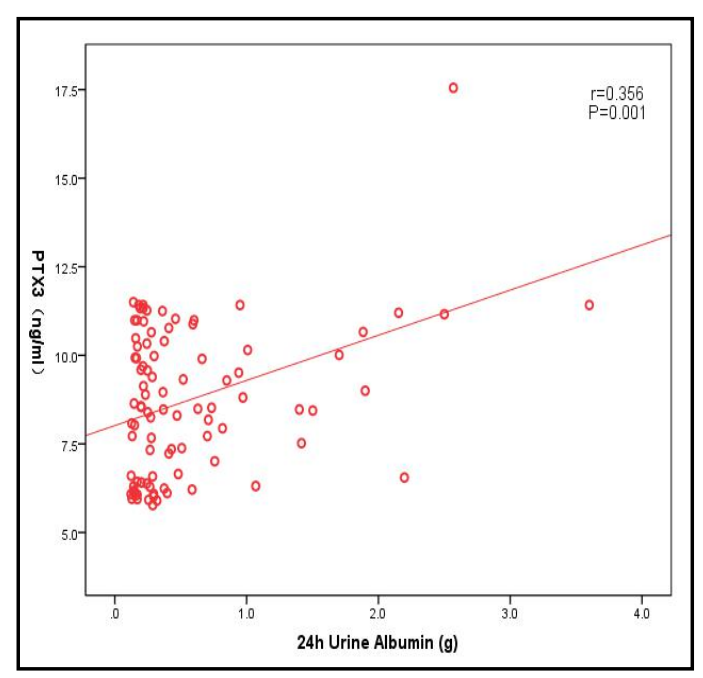

Fig. 4. PTX3 positively correlated with $24 \mathrm{~h}$ urine albumin.

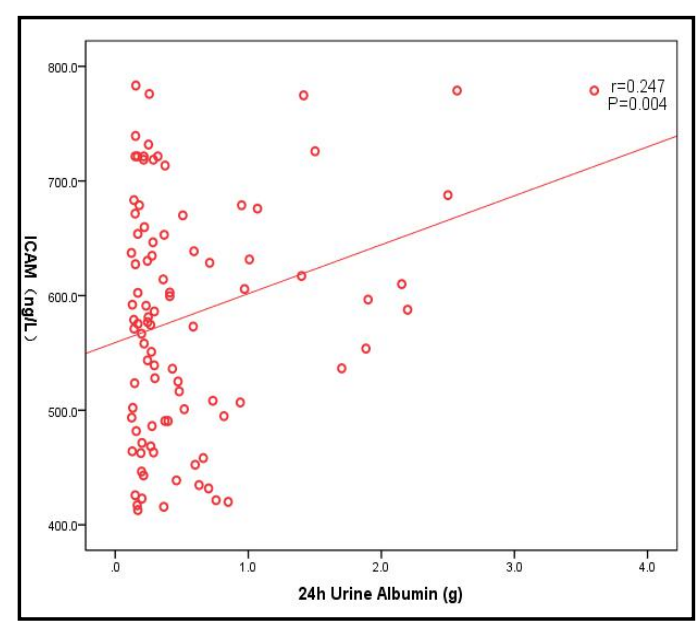

Fig. 6. ICAM positively correlated with $24 \mathrm{~h}$ urine albumin.

\section{KARGER}




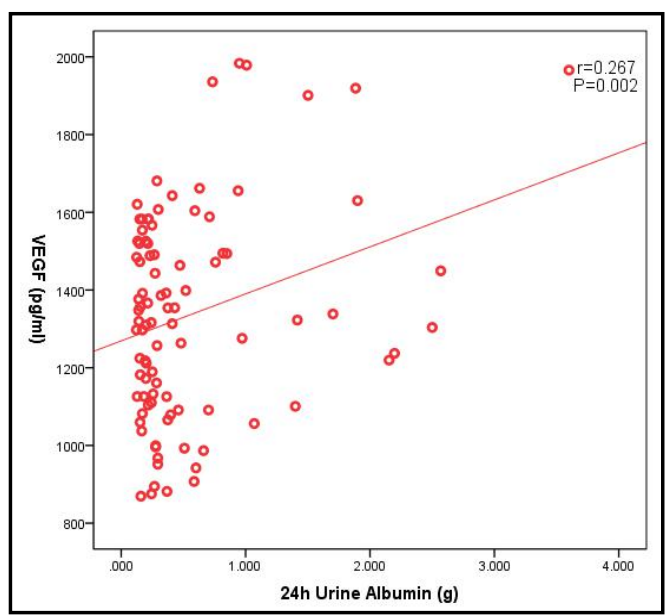

Fig. 7. VEGF positively correlated with $24 \mathrm{~h}$ urine albumin.

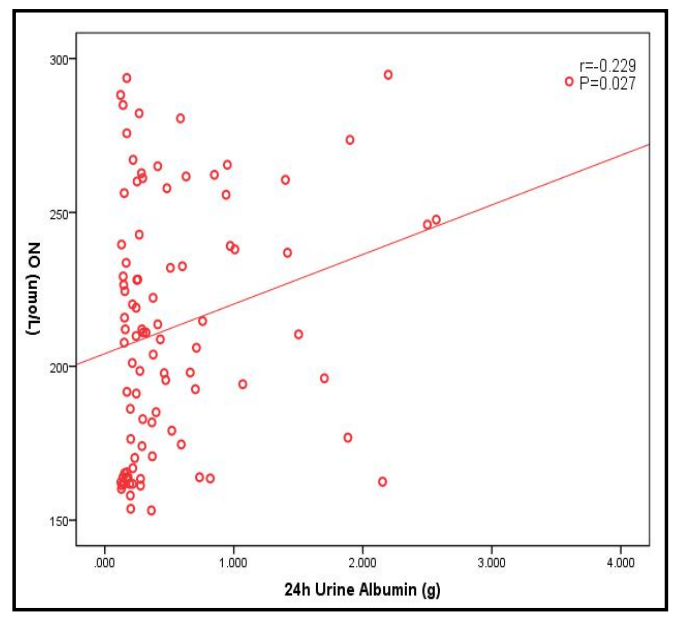

Fig. 8. NO negatively correlated with $24 \mathrm{~h}$ urine albumin.

\section{Efficacy assessment: chronic} inflammatory state and endothelial cell function. Urinary albumin decreased in a time-dependent manner in the treatment group (Table 5). Urinary albumin dropped from $267.41 \pm 24.44 \mathrm{mg} / \mathrm{dl}$ to $196.19 \pm 19.94 \mathrm{mg} / \mathrm{dl}$ at 1 month after $\mathrm{CaD}$ treatment and then gradually decreased thereafter. The urinary albumin dropped to $126.69 \pm 16.67 \mathrm{mg} / \mathrm{dl}$ after 3 months of treatment, which significantly differed from that before treatment $(\mathrm{P}<0.001)$. In contrast, there was no significant difference in urinary albumin among the different observation time points in the observation group. After 3 months of CaD treatment, both the 24 h urinary albumin and $24 \mathrm{~h}$ urinary protein levels significantly decreased $(\mathrm{P}<0.05)$ (Table 4); however, Cys $\mathrm{C}$ and the Cys C-based GFR did not change significantly (Table 4). No significant change occurred in $24 \mathrm{~h}$

Table 3. Logistic-regression analysis

\begin{tabular}{lccc}
\hline Variables & OR & $95 \% \mathrm{CI}$ & $\mathrm{P}$ \\
\hline HbAlc & 3.304 & $1.228 \sim 8.884$ & 0.012 \\
PTX3 & 2.761 & $1.358 \sim 5.615$ & 0.004 \\
NO & 0.941 & $0.905 \sim 0.979$ & 0.003 \\
\hline
\end{tabular}

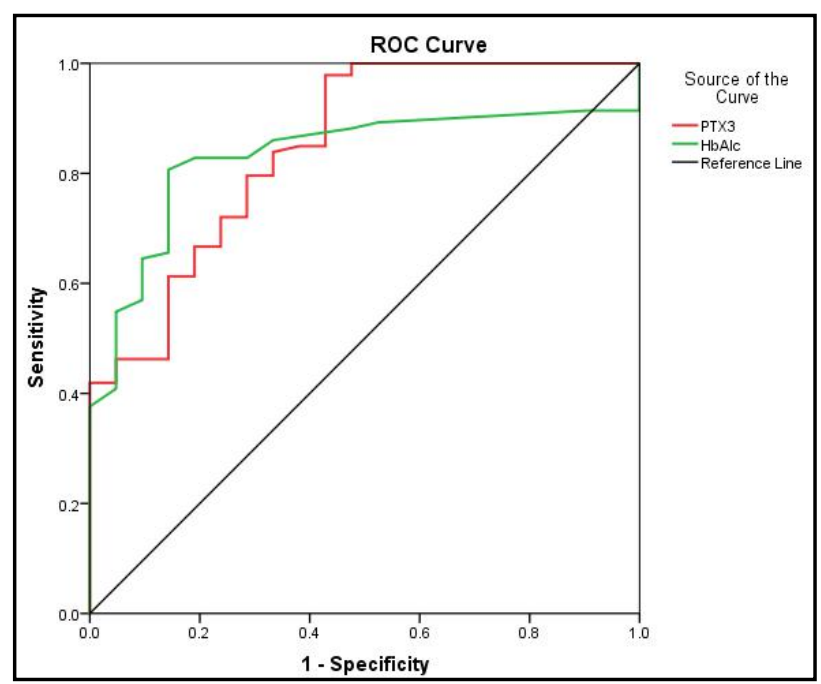

Fig. 9. ROC curve of PTX3 and HbAlc in DKD. urinary albumin, 24 urinary protein or the GFR in the observation group after three months.

Moreover, the microinflammatory indices (PTX3, MCP-1, hs-CRP and ICAM) and endothelial injury indices (VEGF, NO and ET-1) significantly improved in the patients following three months of $\mathrm{CaD}$ administration (Table 4). The above indices did not change in the observation group. This finding suggests that $\mathrm{CaD}$ improved the urinary protein excretion in the patients with DKD by ameliorating the chronic inflammatory state and endothelial cell function of these patients. 
Safety assessment. The patients of the medication group showed no significant changes in vital signs (e.g., blood pressure) or various biochemical indices (e.g., hepatic function, HbAlc, albumin and blood lipids) between the values before and those after treatment. Among the fifty patients were given $\mathrm{CaD}$, no adverse drug reactions or severe adverse reactions were found. No severe adverse events associated with the tested drug were observed. There were no adverse events leading to death.

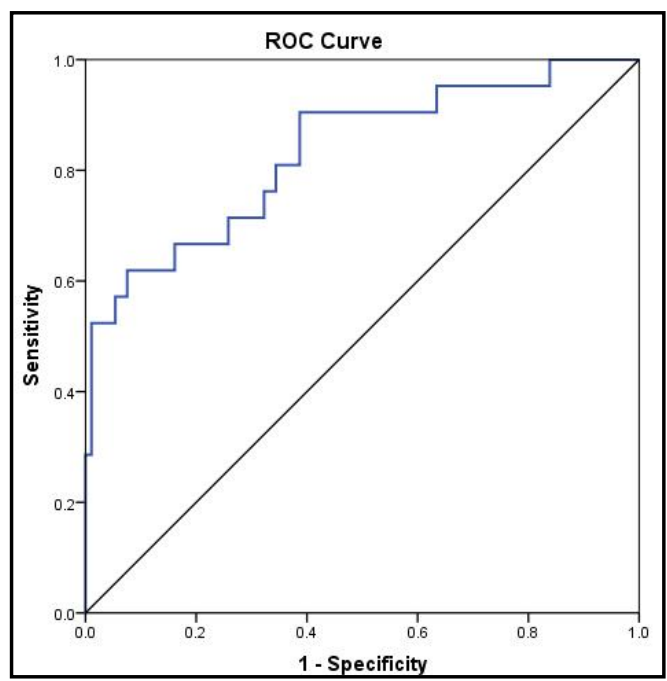

Fig. 10. ROC curve of NO in DKD.

Table 4. CaD reduced the urinary protein in the patients with DKD by improving the chronic inflammatory state and endothelial cell function. Mean \pm SD for normally distributed data and median (range) for nonparametric data. $\mathrm{GFR}=$ glomerular filtration rate; $\mathrm{CVD}=$ cardiovascular disease; $\mathrm{HDL}=$ high density lipoprotein; hsCRP=high-sensitivity protein; LDL=low-density lipoprotein; PTX3=pentraxin 3; HbAlc=glycoseylated hemoglobin; MCP-1=monocyte chemotactic protein 1; ICAM=intercellular cell adhesion molecule-1; VEGF=vascular endothelial growth factor; ET-1=endothelin-1; eNOS=endothelial nitric oxide synthase; $\mathrm{NO}=$ nitric oxide

\begin{tabular}{|c|c|c|c|c|c|c|c|c|}
\hline \multirow{2}{*}{ Parameter } & \multicolumn{2}{|c|}{ Baseline } & \multicolumn{2}{|c|}{3 months bater } & \multirow{2}{*}{$\begin{array}{r}1 / 2 \\
(\mathrm{P})\end{array}$} & \multirow{2}{*}{$\begin{array}{l}2 / 4 \\
(\mathrm{P})\end{array}$} & \multirow{2}{*}{$\begin{array}{l}1 / 3 \\
(\mathrm{P})\end{array}$} & \multirow{2}{*}{$\begin{array}{l}3 / 4 \\
(\mathrm{P})\end{array}$} \\
\hline & 1.treatment group & 2.observation group & 3.treatment group & 4.observation group & & & & \\
\hline $\mathrm{n}$ & 50 & 50 & 50 & 50 & & & & \\
\hline Duration of DM (years) & $17.44 \pm 7.63$ & $17.54 \pm 7.80$ & / & / & NS & / & / & / \\
\hline History of CVD, $n(\%)$ & $7(14)$ & $8(16)$ & / & / & NS & / & / & / \\
\hline Statin taking history n (\%) & $10(20)$ & $11(22)$ & / & / & NS & / & / & / \\
\hline Age (years) & $57.97 \pm 11.65$ & $61.43 \pm 10.03$ & / & / & NS & / & / & / \\
\hline $\operatorname{Sex}(M / F)$ & $24 / 26$ & $27 / 23$ & / & / & NS & / & / & / \\
\hline Systolic blood pressure ( $\mathrm{mmHg}$ ) & $127.72 \pm 15.24$ & $127.38 \pm 16.20$ & $127.79 \pm 16.53$ & $127.42 \pm 15.43$ & NS & NS & NS & NS \\
\hline Diastolic blood pressure (mmHg) & $70.41 \pm 10.86$ & $70.81 \pm 11.74$ & $70.21 \pm 11.01$ & $70.64 \pm 10.98$ & NS & NS & NS & NS \\
\hline Mean arterial pressure ( $\mathrm{mmHg}$ ) & $87.51 \pm 13.18$ & $85.00 \pm 17.36$ & $88.07 \pm 12.11$ & $86.03 \pm 14.57$ & NS & NS & NS & NS \\
\hline ACR (mg/g) & $274.37(106,426)$ & $244.73(54,267)$ & / & / & NS & / & / & / \\
\hline urinary albumin $(\mathrm{mg} / \mathrm{dl})$ & $267.42 \pm 24.44$ & $262.23 \pm 42.90$ & $126.70 \pm 16.67$ & $304.82 \pm 38.30$ & NS & NS & $<0.001$ & $<0.001$ \\
\hline $24 \mathrm{~h}$ urinary albumin $(\mathrm{g})$ & $0.25(0.15,0.49)$ & $0.21(0.13,0.53)$ & $0.16(0.11,0.32)$ & $0.31(0.19,0.70)$ & NS & NS & 0.010 & $<0.001$ \\
\hline $24 \mathrm{~h}$ urinary protein $(\mathrm{g})$ & $0.55(0.20,0.60)$ & $\begin{array}{c}0.50 \\
(0.16,0.62)\end{array}$ & $0.31(0.14,0.42)$ & $0.72(0.25,0.91)$ & NS & NS & 0.014 & $<0.001$ \\
\hline $\begin{array}{l}\mathrm{eGFR} \\
{\left[\mathrm{ml} \cdot \mathrm{min}^{-1} \cdot\left(1.73 \mathrm{~m}^{2}\right)^{-1}\right]}\end{array}$ & $105.82 \pm 12.38$ & $107.12 \pm 9.53$ & $106.64 \pm 11.08$ & $106.12 \pm 8.44$ & NS & NS & NS & NS \\
\hline Total Cholesterol (mmol/L) & $4.87 \pm 1.12$ & $5.05 \pm 1.33$ & $4.87 \pm 1.12$ & $5.05 \pm 1.33$ & NS & NS & NS & NS \\
\hline Triglyceride (mmol/L) & $1.74 \pm 1.05$ & $2.08 \pm 1.36$ & $1.75 \pm 0.93$ & $2.03 \pm 1.04$ & NS & NS & NS & NS \\
\hline $\mathrm{LDL}(\mathrm{mmol} / \mathrm{L})$ & $2.91 \pm 0.88$ & $3.05 \pm 0.91$ & $3.02 \pm 0.89$ & $2.93 \pm 0.92$ & NS & NS & NS & NS \\
\hline HDL (mmol/L) & $1.19 \pm 0.33$ & $1.15 \pm 0.30$ & $1.16 \pm 0.25$ & $1.14 \pm 0.37$ & NS & NS & NS & NS \\
\hline HBAlc (\%) & $8.05 \pm 2.06$ & $8.68 \pm 1.80$ & $7.52 \pm 1.77$ & $8.37 \pm 1.74$ & NS & NS & NS & NS \\
\hline Alb (g/L) & $43.20 \pm 3.30$ & $42.49 \pm 4.10$ & $42.20 \pm 3.70$ & $43.19 \pm 3.10$ & NS & NS & NS & NS \\
\hline GPT (U/L) & $22.46 \pm 13.10$ & $20.12 \pm 12.41$ & $21.46 \pm 12.04$ & $21.12 \pm 10.47$ & NS & NS & NS & NS \\
\hline GOT(U/L) & $20.77 \pm 8.86$ & $19.30 \pm 7.32$ & $19.97 \pm 7.83$ & $19.74 \pm 8.57$ & NS & NS & NS & NS \\
\hline $\mathrm{SB}(\mathrm{mg} / \mathrm{dl})$ & $11.64 \pm 6.43$ & $9.93 \pm 4.08$ & $10.53 \pm 5.95$ & $10.03 \pm 5.92$ & NS & NS & NS & NS \\
\hline $\mathrm{SB}^{\prime}(\mathrm{mg} / \mathrm{dl})$ & $3.62 \pm 1.60$ & $3.56 \pm 1.31$ & $3.57 \pm 1.54$ & $3.63 \pm 1.53$ & NS & NS & NS & NS \\
\hline hsCRP (mg/l) & $2.23 \pm 0.37$ & $1.83 \pm 0.70$ & $1.15 \pm 1.09$ & $1.94 \pm 0.60$ & NS & NS & 0.04 & NS \\
\hline MCP-1(ng/L) & $194.81 \pm 41.27$ & $207.64 \pm 47.00$ & $172.81 \pm 40.97$ & $209.64 \pm 64.00$ & NS & NS & 0.009 & $<0.001$ \\
\hline PTX3(ng/ml) & $8.71 \pm 2.43$ & $8.67 \pm 1.84$ & $7.40 \pm 1.77$ & $8.37 \pm 2.05$ & NS & NS & 0.008 & 0.01 \\
\hline ICAM(ng/L) & $574.24 \pm 99.31$ & $588.67 \pm 97.68$ & $511.96 \pm 130.98$ & $579.67 \pm 85.04$ & NS & NS & 0.013 & 0.008 \\
\hline $\operatorname{VEGF}(\mathrm{ng} / \mathrm{ml})$ & $1.31 \pm 0.26$ & $1.35 \pm 0.28$ & $1.13 \pm 0.28$ & $1.38 \pm 0.57$ & NS & NS & 0.003 & $<0.001$ \\
\hline $\mathrm{ET}-1(\mathrm{pg} / \mathrm{ml})$ & $209.65 \pm 37.23$ & $215.36 \pm 41.08$ & $186.03 \pm 42.20$ & $229.86 \pm 53.75$ & NS & NS & 0.004 & $<0.001$ \\
\hline $\operatorname{eNOS}(\mathrm{U} / \mathrm{L})$ & $50.52 \pm 10.60$ & $53.14 \pm 10.37$ & $52.29 \pm 10.17$ & $50.54 \pm 9.40$ & NS & NS & NS & NS \\
\hline $\mathrm{NO}($ umol/L) & $150.61 \pm 37.57$ & $141.01 \pm 31.95$ & $206.54 \pm 40.56$ & $145.06 \pm 39.59$ & NS & NS & 0.001 & $<0.001$ \\
\hline
\end{tabular}




\section{Cellular Physiology Cell Physiol Biochem 2018;51:1119-1133 \begin{tabular}{ll|l} 
and Biochemistry Published onIIne: 24 November 2018 & $\begin{array}{l}\text { (c) } 2018 \text { The Author(s). Published by S. Karger AG, Basel } \\
\text { www.karger.com/cpb }\end{array}$ \\
\hline
\end{tabular} Zhou et al.: Calcium Dobesilate Can Be Used to Treat Diabetic Nephropathy}

\section{Discussion}

In 2007, the National Kidney

Foundation Kidney Disease

Outcomes Quality Initiative

(NKF-K/DOQI) guideline

proposed that in the majority of

DM patients, renal injury should

be considered a result of DM

in patients showing any of the

following: (1) macroalbuminuria;

(2) diabetic retinopathy accompanied with microalbuminuria; or (3) microalbuminuria in type 1 DM with a course of DM of at least 10 years. In 2014, the Study Group on Diabetic Microvascular Complications of the Chinese Diabetes Society suggested the following diagnostic criteria for DKD: (1) macroalbuminuria; (2) diabetic retinopathy accompanied with any stage of CKD; and (3) microalbuminuria in type $1 \mathrm{DM}$ with a course of DM of at least 10 years [23]. The type $2 \mathrm{DM}$ patients included in the present study exhibited diabetic retinopathy and had urinary protein excretion, in line with the diagnostic criteria for DKD.

In the prospective study, urinary albumin decreased in a time-dependent manner in the treatment group after $\mathrm{CaD}$ administration; no difference was found in urinary albumin among the different time points in the observation group. Following three months of $\mathrm{CaD}$ treatment, both the $24 \mathrm{~h}$ urinary albumin and $24 \mathrm{~h}$ urinary protein levels significantly decreased; however, Cys $\mathrm{C}$ and the Cys C-based GFR did not change. In the observation group, $24 \mathrm{~h}$ urinary albumin, $24 \mathrm{~h}$ urinary protein and the GFR exhibited no significant change after three months. The safety assessment results indicated that vital signs (e.g., blood pressure) and various biochemical indices (hepatic function, HbAlc, albumin and blood lipids) did not differ significantly before and after $\mathrm{CaD}$ treatment. No adverse reactions were observed during treatment. The results show that $\mathrm{CaD}$ can effectively reduce urinary protein excretion and that this treatment is tolerated by patients with DKD.

In the present study, we found that the DKD patients had significantly higher inflammatory indices, such as PTX3, MCP-1 and ICAM, and endothelial cell function-related indices, such as VEGF and ET-1, than the DM patients without proteinuria; in contrast, NO was significantly reduced. Additionally, the inflammatory indices, such as PTX3, MCP-1 and ICAM, as well as the endothelial cell function-related indices, such as VEGF and ET-1, were positively correlated with $24 \mathrm{~h}$ urinary albumin; NO was negatively correlated with $24 \mathrm{~h}$ urinary albumin. Furthermore, logistic regression analysis showed that PTX3 and HbAlc were risk factors for DKD, whereas NO was a protective factor. Following three months of CaD treatment, urinary albumin decreased in the DKD patients in a time-dependent manner, and $24 \mathrm{~h}$ urinary protein decreased, but the GFR did not change significantly. Additionally, the levels of both microinflammatory indices (PTX3, MCP-1, hs-CRP and ICAM) and endothelial injury indices (VEGF, ET-1) were significantly lower after treatment than before treatment. NO were significantly higher. These findings suggest that CaD may improve urinary protein excretion by ameliorating the chronic inflammatory state and improving endothelial cell function in patients with DKD.

Microalbuminuria is an early manifestation of DKD as well as an independent risk factor for the morbidity and mortality of CVD; this finding suggests that systemic endothelial function impairment may be a cause of CVD and DKD in DM[24]. DKD is known to be associated with an early elevation and a late decrease in the GFR. We selected DKD patients who had proteinuria but a normal GFR to explore the role of $\mathrm{CaD}$ in the treatment of early DKD. Glomerular capillary angiogenesis may be a cause of the early elevation in the GFR. A streptomycin-induced DM mouse model showed an increased number and length of glomerular capillaries as well as increased cross-sectional area of the capillaries [25]. Similarly, an increased number of new blood vessels in the kidney has also been observed in a human study [26]. These new blood vessels have a thin and immature basement membrane, 


\section{Cellular Physiology Cell Physiol Biochem 2018;51:1119-1133

 \\ Zhou et al.: Calcium Dobesilate Can Be Used to Treat Diabetic Nephropathy}

endothelial swelling and decreased selective filtration capacity, which may be related to microalbuminuria. In the late stage of DKD, the GFR is reduced, and the number of glomerular capillaries is decreased. If DKD patients with a reduced GFR are selected, the subjects may not reflect the anti-proliferative effect of $\mathrm{CaD}$, thus affecting the measured efficacy.

The characteristic fluctuation in the GFR from high to low in DKD may be related to VEGF, as VEGF also exhibits a similar fluctuation [27]. VEGF is closely associated with diabetic microangiopathy, but the mechanism has been investigated more often in diabetic retinopathy, which is characterised by retinal angiogenesis with abnormal vasculature and filterability. Without laser therapy, proliferative diabetic retinopathy can lead to irreversible retinal damage and blindness. Although further research is needed, theoretically, anti-VEGF therapy shows some prospects in proliferative diabetic retinopathy [28]. In the kidney, VEGF is mainly produced by podocytes. VEGF expression is increased in the early stage of DM, which can promote angiogenesis. However, in the late stage of DM, VEGF expression decreases, perhaps due to a decreased number of podocytes, resulting in fewer renal capillaries and a reduced GFR. Anti-VEGF therapy is effective in an early DKD model [29]. In the present study, we found that the serum VEGF level in the DKD patients $(1.28 \pm 0.23 \mathrm{ng} /$ $\mathrm{ml}$ ) was significantly higher than that in the DM patients without urinary protein excretion $(0.94 \pm 0.21 \mathrm{ng} / \mathrm{ml})$; additionally, VEGF was positively correlated with $24 \mathrm{~h}$ urinary protein, in agreement with the results of the above study.

The NO level decreased in DKD, which could be related to the decrease in the NO level caused by human gene polymorphisms [30]. This finding was also found in eNOSdeficient mice. Streptomycin-induced mice showed the early pathological changes of DKD, namely, glomerular basement membrane thickening and mesangial dilatation. With the same treatment, eNOS-knockout mice showed the pathological changes of late DKD, such as mesangial cell dissolution, Kimmelstiel-Wilson (K-W) nodule formation, arterial hyalinisation and renal tubulointerstitial alteration. One potential reason for this finding may be that the self-regulation of glomeruli is impaired, leading to increased intraglomerular pressure. Hypotensive therapy with hydralazine can prevent renal injury in eNOS-knockout mice, supporting the above inference [31]. Another possible pathogenic mechanism is 'VEGFeNOS uncoupling. VEGF generally induces NO production, which has a protective effect on glomerular endothelial cells. However, in the case of NO decline, VEGF is over-generated, inducing an inflammatory state, abnormal endothelial cell proliferation and macrophage infiltration; these proliferative and inflammatory events interact with each other, promoting disease progression [32]. The role of NO in regulating VEGF was also found in diabetic retinopathy in eNOS-knockout mice. Compared with wild-type DM mice, the eNOS-knockout mice had retinopathy that progressed more rapidly, as characterised by retinal capillary formation and increased retinal vascular permeability in abnormal cells [33]. The present study also demonstrated that serum NO levels were significantly lower in the DKD patients than in the DM patients without urine protein excretion and were negatively correlated with urinary protein levels in the patients. Logistic regression analysis results showed that NO is a protective factor for $\mathrm{DKD}$, and ROC results suggest that the NO level has a predictive role in DKD. These findings are in agreement with previous findings.

In addition to angiogenesis, microinflammation plays an important role in the development and progression of DKD[34-38]. Both intercellular cell adhesion molecule-1 (ICAM-1) and vascular cell adhesion molecule-1 (VCAM-1) have been found to be upregulated in DKD; as suggested by their names, these two factors facilitate the adhesion of inflammatory cells and recruit circulating immune cells $[39,40]$. In the present study, we found that the levels of MCP-1, PTX3 and ICAM were significantly elevated in the DKD patients compared with those in the DM patients without proteinuria; these factors were positively correlated with the urine protein level in these patients. Logistic regression analysis results revealed that PTX3 is a risk factor for DKD, and ROC results suggested that PTX3 has a predictive role in DKD. 


\section{Cellular Physiology Cell Physiol Biochem 2018;51:1119-1133

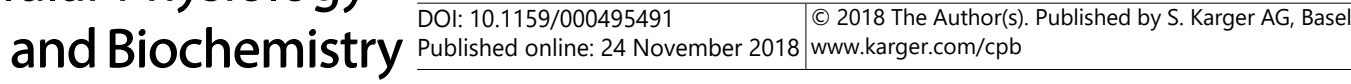 \\ Zhou et al.: Calcium Dobesilate Can Be Used to Treat Diabetic Nephropathy}

In the circulation of type 2 DM patients, ET-1 is generally elevated [41], and this elevation has been shown to affect insulin sensitivity in healthy populations. A cross-sectional study also demonstrated that both serum and urine ET-1 levels were significantly elevated in type 2 DM populations and correlated with urinary protein excretion and blood pressure [42]. In the present study, we also showed that the serum ET-1 level was elevated in DKD patients and positively correlated with the urine protein level in these patients. This finding is consistent with the results of previous studies.

However, there are also some limitations for the application of CaD in DKD because both in vivo and in vitro, $\mathrm{CaD}$ interferes to some extent with the serum creatinine measured by the sarcosine oxidase assay, which causes difficulty in the assessment of renal function. Once the GFR declines in DKD patients, the disease progression begins to accelerate; these patients also have more cardiovascular complications than typical CKD patients and even enter dialysis earlier. This situation results in inconveniences and safety risks for patient follow up. But research using big data suggests that $\mathrm{CaD}$ does not affect the Cys $\mathrm{C}$ assay; thus, the use of Cys $\mathrm{C}$ is proposed for the assessment of renal function levels in patients using CaD. Cys $\mathrm{C}$ is commonly used as an indicator for assessing renal function and may be more sensitive than the traditional method [43]. Given that CaD interferes with the enzymatic assay of creatinine, we used Cys $\mathrm{C}$ and the GFR calculated using the CKD-EPI Cys $\mathrm{C}$ equation to assess renal function. The results showed that neither the serum Cys $\mathrm{C}$ level nor the GFR changed significantly in the patients after treatment compared with those before CaD treatment.

Diabetic nephropathy and retinopathy pathogenesis share some similarities: both are proliferative lesions and are associated with a microinflammatory state [44]. CaD can be used to treat diabetic retinopathy through anti-oxidation and anti-free radical mechanisms, which has proven efficacy [15]. CaD is also extensively used to treat diabetic fundus oculi disease; however, little research has been dedicated to its clinical efficacy and administration safety in patients with diabetic nephropathy. In the present study, we found that the urinary albumin decreased in a time-dependent manner in the DKD patients following three months of treatment with $\mathrm{CaD}$; additionally, $24 \mathrm{~h}$ urinary protein decreased, whereas the GFR did not change significantly. Safety indices, such as hepatic function, also did not change significantly after treatment compared with those before treatment. Moreover, the microinflammatory indices (PTX3, MCP-1, hs-CRP and ICAM) and endothelial injury markers (VEGF, ET-1) were significantly reduced compared with those before treatment, except NO was significantly increased. Our preliminary results show that by using $\mathrm{CaD}$ in patients with DKD may improve urinary protein excretion by alleviating the chronic inflammatory state and improving endothelial cell function and that $\mathrm{CaD}$ is safe and effective.

We acknowledge several limitations of this study. First, our diagnosis of DKD is based on clinical manifestations, not on renal biopsy. Second, although described as a trial to assess efficacy and safety, the period of our study is limited in length so can only really be expected to be a pilot. Third, due to the small number of cases and the short period of follow-up, our findings need to be further verified by multi-centre, double-blind, randomised, controlled studies.

\section{Conclusion}

CaD may improve urinary protein excretion by ameliorating the chronic inflammatory state and improving endothelial cell function. 


\section{Cellular Physiology Cell Physiol Biochem 2018;51:1119-1133 \begin{tabular}{l|l|l} 
and Biochemistry Published onlIne: 24 November 2018 & $\begin{array}{l}\text { (c) } 2018 \text { The Author(s). Published by S. Karger AG, Basel } \\
\text { www.karger.com/cpb }\end{array}$ \\
\hline
\end{tabular} \\ Zhou et al.: Calcium Dobesilate Can Be Used to Treat Diabetic Nephropathy}

\section{Abbreviations}

DKD (diabetic kidney disease); CKD (chronic kidney disease); DM (diabetes mellitus); ESRD (end-stage renal disease); USRDS (United States Renal Data System); RAAS (reninangiotensin-aldosterone system); ACEI (angiotensin-converting enzyme inhibitor); ARB (angiotensin II receptor blockade); GFR (glomerular filtration rate); $\mathrm{CaD}$ (Calcium dobesilate); ADA (American Diabetes Association ); ACR (albumin/creatinine ratio); CVD (cardiovascular diseases); Cys (C, cystatin C); hs-CRP (high-sensitivity C-reactive protein); VEGF (vascular endothelial growth factor); ET-1 (endothelin-1); MCP-1 (monocyte chemotactic protein 1); ICAM (intercellular adhesion molecule-1); eNOS (endothelial nitric oxide synthase); NO (nitric oxide; PTX3, pentraxin 3); ROC (receiver operating characteristic); NKF-K/DOQI (National Kidney Foundation Kidney Disease Outcomes Quality Initiative).

\section{Acknowledgements}

The study was supported in part by the National Natural Science Foundation of China (81370794 and 81570604) as well as by a grant (ZHYY-ZXYJHZX-1-02) from the Shanghai Municipal Commission of Health and Family Planning. We also thank Shanghai Zhaohui Pharmaceutical Co., Ltd.

Zhaohui Ni and Yijun Zhou conceived and designed the study; Yijun Zhou performed the study, collected and analyzed the study data, wrote the manuscript; Yijun Zhou, Chaojun Qi, Shu Li, Xinghua Shao, Shan Mou participated in collection and interpretation of the data. Zhaohui Ni revised the manuscript. All authors read and approved the manuscript.

\section{Disclosure Statement}

The authors do not have any possible conflicts of interest to disclose.

\section{References}

1 Mohamed Q, Gillies MC, Wong TY: Management of diabetic retinopathy: a systematic review. JAMA 2007;298:902-916.

-2 Mathers CD, Loncar D: Projections of global mortality and burden of disease from 2002 to 2030. PLoS Med 2006;3:e442.

3 Bragg F, Holmes MV, Iona A, Guo Y, Du H, Chen Y, Bian Z, Yang L, Herrington W, Bennett D, Turnbull I, Liu Y, Feng S, Chen J, Clarke R, Collins R, Peto R, Li L, Chen Z, China Kadoorie Biobank Collaborative G: Association Between Diabetes and Cause-Specific Mortality in Rural and Urban Areas of China. JAMA 2017;317:280289.

4 Mathiesen ER, Hommel E, Hansen HP, Smidt UM, Parving HH: Randomised controlled trial of long term efficacy of captopril on preservation of kidney function in normotensive patients with insulin dependent diabetes and microalbuminuria. BMJ 1999;319:24-25.

5 Gurley SB, Coffman TM: The renin-angiotensin system and diabetic nephropathy. Semin Nephrol 2007;27:144-152.

-6 Hostetter TH, Rosenberg ME, Ibrahim HN, Juknevicius I: Aldosterone in progressive renal disease. Semin Nephrol 2001;21:573-579.

7 Schrier RW, Masoumi A, Elhassan E: Aldosterone: role in edematous disorders, hypertension, chronic renal failure, and metabolic syndrome. Clin J Am Soc Nephrol 2010;5:1132-1140.

-8 Schrier RW: Aldosterone 'escape' vs 'breakthrough'. Nat Rev Nephrol 2010;6:61.

-9 Schjoedt KJ, Andersen S, Rossing P, Tarnow L, Parving HH: Aldosterone escape during blockade of the renin-angiotensin-aldosterone system in diabetic nephropathy is associated with enhanced decline in glomerular filtration rate. Diabetologia 2004;47:1936-1939. 


\section{Cellular Physiology Cell Physiol Biochem 2018;51:1119-1133

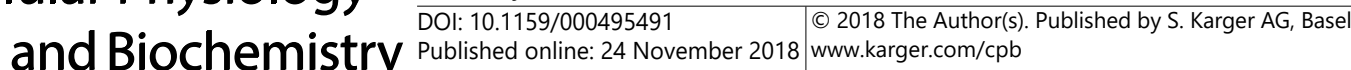 \\ Zhou et al.: Calcium Dobesilate Can Be Used to Treat Diabetic Nephropathy}

10 Stehouwer CD, Gall MA, Twisk JW, Knudsen E, Emeis JJ, Parving HH: Increased urinary albumin excretion, endothelial dysfunction, and chronic low-grade inflammation in type 2 diabetes: progressive, interrelated, and independently associated with risk of death. Diabetes 2002;51:1157-1165.

11 Persson F, Rossing P, Hovind P, Stehouwer CD, Schalkwijk CG, Tarnow L, Parving HH: Endothelial dysfunction and inflammation predict development of diabetic nephropathy in the Irbesartan in Patients with Type 2 Diabetes and Microalbuminuria (IRMA 2) study. Scand J Clin Lab Invest 2008;68:731-738.

12 Nielsen SE, Schjoedt KJ, Rossing K, Persson F, Schalkwijk CG, Stehouwer CD, Parving HH, Rossing P: Levels of NT-proBNP, markers of low-grade inflammation, and endothelial dysfunction during spironolactone treatment in patients with diabetic kidney disease. J Renin Angiotensin Aldosterone Syst 2013;14:161-166.

13 Ribeiro ML, Caillon P, Gamba G, Cunhavaz J, DX-retinopathy study group: Efficacy of calcium dobesilate (Doxium(R)) on the blood-retinal barrier permeability in early diabetic retinopathy: a double-blind study. Invest Ophthalmol Vis Sci, 2004, 45:4153.

14 Akbulut B: Calcium dobesilate and oxerutin: effectiveness of combination therapy. Phlebology 2010;25:6671.

15 Zhang X, Liu W, Wu S, Jin J, Li W, Wang N: Calcium dobesilate for diabetic retinopathy: a systematic review and meta-analysis. Sci China Life Sci 2015;58:101-107.

16 Graber R, Farine JC, Losa GA: Calcium Dobesilate protects human peripheral blood mononuclear cells from oxidation and apoptosis. Apoptosis 1998;3:41-49.

$\checkmark 17$ Szabo ME, Haines D, Garay E, Chiavaroli C, Farine JC, Hannaert P, Berta A, Garay RP: Antioxidant properties of calcium dobesilate in ischemic/reperfused diabetic rat retina. Eur J Pharmacol 2001;428:277-286.

18 Rabe E, Jaeger KA, Bulitta M, Pannier F: Calcium dobesilate in patients suffering from chronic venous insufficiency: a double-blind, placebo-controlled, clinical trial. Phlebology 2011;26:162-168.

19 Hall JF: Modern management of hemorrhoidal disease. Gastroenterol Clin North Am 2013;42:759-772.

20 Jafarey M, Changizi Ashtiyani S, Najafi H: Calcium dobesilate for prevention of gentamicin-induced nephrotoxicity in rats. Iran J Kidney Dis 2014;8:46-52.

-21 Zhang X: Therapeutic effects of calcium dobesilate on diabetic nephropathy mediated through reduction of expression of PAI-1. Exp Ther Med 2013;5:295-299.

-22 Inker LA, Schmid CH, Tighiouart H, Eckfeldt JH, Feldman HI, Greene T, Kusek JW, Manzi J, Van Lente F, Zhang YL, Coresh J, Levey AS, Investigators C-E: Estimating glomerular filtration rate from serum creatinine and cystatin C. N Engl J Med 2012;367:20-29.

23 Chinese Diabetes Society: The expert consensus of diabetes nephropathy prevention and control (2014 edition). China Journal of diabetes 2014;6:792-801.

24 Gerstein HC, Mann JF, Yi Q, Zinman B, Dinneen SF, Hoogwerf B, Halle JP, Young J, Rashkow A, Joyce C, Nawaz S, Yusuf S, Investigators HS: Albuminuria and risk of cardiovascular events, death, and heart failure in diabetic and nondiabetic individuals. JAMA 2001;286:421-426.

-25 Nyengaard JR, Rasch R: The impact of experimental diabetes mellitus in rats on glomerular capillary number and sizes. Diabetologia 1993;36:189-194.

-26 Osterby R, Nyberg G: New vessel formation in the renal corpuscles in advanced diabetic glomerulopathy. J Diabet Complications 1987;1:122-127.

27 Nakagawa T, Kosugi T, Haneda M, Rivard CJ, Long DA: Abnormal angiogenesis in diabetic nephropathy. Diabetes 2009;58:1471-1478.

28 Tremolada G, Del Turco C, Lattanzio R, Maestroni S, Maestroni A, Bandello F, Zerbini G: The role of angiogenesis in the development of proliferative diabetic retinopathy: impact of intravitreal anti-VEGF treatment. Exp Diabetes Res 2012;2012:728325.

29 Eleftheriadis T, Antoniadi G, Pissas G, Liakopoulos V, Stefanidis I: The renal endothelium in diabetic nephropathy. Ren Fail 2013;35:592-599.

-30 Ezzidi I, Mtiraoui N, Mohamed MB, Mahjoub T, Kacem M, Almawi WY: Association of endothelial nitric oxide synthase Glu298Asp, 4b/a, and -786T >C gene variants with diabetic nephropathy. J Diabetes Complications 2008;22:331-338.

-31 Nakagawa T, Sato W, Glushakova O, Heinig M, Clarke T, Campbell-Thompson M, Yuzawa Y, Atkinson MA, Johnson RJ, Croker B: Diabetic endothelial nitric oxide synthase knockout mice develop advanced diabetic nephropathy. J Am Soc Nephrol 2007;18:539-550.

-32 Nakagawa T, Sato W, Kosugi T, Johnson RJ: Uncoupling of VEGF with endothelial NO as a potential mechanism for abnormal angiogenesis in the diabetic nephropathy. J Diabetes Res 2013;2013:184539. 


\section{Cellular Physiology Cell Physiol Biochem 2018;51:1119-1133

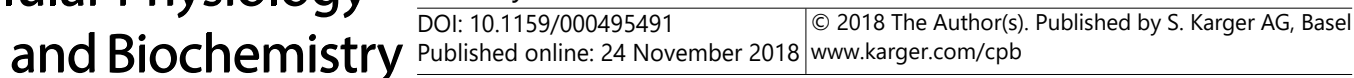

33 Li Q Verma A, Han PY, Nakagawa T, Johnson RJ, Grant MB, Campbell-Thompson M, Jarajapu YP, Lei B, Hauswirth WW: Diabetic eNOS-knockout mice develop accelerated retinopathy. Invest Ophthalmol Vis Sci 2010;51:5240-5246.

-34 Lacava V, Pellicano V, Ferrajolo C, Cernaro V, Visconti L, Conti G, Buemi M, Santoro D: Novel avenues for treating diabetic nephropathy: new investigational drugs. Expert Opin Investig Drugs 2017;26:445-462.

-35 Navarro-Gonzalez JF, Mora-Fernandez C, Muros de Fuentes M, Garcia-Perez J: Inflammatory molecules and pathways in the pathogenesis of diabetic nephropathy. Nat Rev Nephrol 2011;7:327-340.

-36 Galkina E, Ley K: Leukocyte recruitment and vascular injury in diabetic nephropathy. J Am Soc Nephrol 2006;17:368-377.

37 Turkmen K: Inflammation, oxidative stress, apoptosis, and autophagy in diabetes mellitus and diabetic kidney disease: the Four Horsemen of the Apocalypse. Int Urol Nephrol 2017;49:837-844.

38 Bertinat R, Westermeier F, Silva P, Shi J, Nualart F, Li X, Yanez AJ: Anti-Diabetic Agent Sodium Tungstate Induces the Secretion of Pro- and Anti-Inflammatory Cytokines by Human Kidney Cells. J Cell Physiol 2017;232:355-362.

-39 Sugimoto H, Shikata K, Hirata K, Akiyama K, Matsuda M, Kushiro M, Shikata Y, Miyatake N, Miyasaka M, Makino H: Increased expression of intercellular adhesion molecule-1 (ICAM-1) in diabetic rat glomeruli: glomerular hyperfiltration is a potential mechanism of ICAM-1 upregulation. Diabetes 1997;46:2075-2081.

40 Seron D, Cameron JS, Haskard DO: Expression of VCAM-1 in the normal and diseased kidney. Nephrol Dial Transplant 1991;6:917-922.

41 Mather KJ, Mirzamohammadi B, Lteif A, Steinberg HO, Baron AD: Endothelin contributes to basal vascular tone and endothelial dysfunction in human obesity and type 2 diabetes. Diabetes 2002;51:3517-3523.

-42 Zanatta CM, Gerchman F, Burttet L, Nabinger G, Jacques-Silva MC, Canani LH, Gross JL: Endothelin-1 levels and albuminuria in patients with type 2 diabetes mellitus. Diabetes Res Clin Pract 2008;80:299-304.

43 Guo X, Hou L, Cheng X, Zhang T, Yu S, Fang H, Xia L, Qi Z, Qin X, Zhang L, Liu Q, Liu L, Chi S, Hao Y, Qiu L: Strong Negative Interference by Calcium Dobesilate in Sarcosine Oxidase Assays for Serum Creatinine Involving the Trinder Reaction. Medicine (Baltimore) 2015;94:e905.

44 Krakoff J, Lindsay RS, Looker HC, Nelson RG, Hanson RL, Knowler WC: Incidence of retinopathy and nephropathy in youth-onset compared with adult-onset type 2 diabetes. Diabetes Care 2003;26:76-81. 